|| ISSN(online): 2589-8698 || ISSN(print): 2589-868X || International Journal of Medical and Biomedical Studies

Available Online at www.ijmbs.info

Volume 3, Issue 2; February: 2019; Page No. 192-197

PubMed (National Library of Medicine ID: 101738825)

Index Copernicus Value 2017: 40.03

\title{
TO ASSESS THE SPECTRUM OF LESIONS IN LYMPH NODES IN HEAD AND NECK REGION
}

\section{Dr. Bipin Gandhi}

Associate Professor Department of Pathology Vedanta Institute of Medical Sciences Dahanu, Palghar, Maharashtra.

Article Info: Received 24 November 2018; Accepted 27 December. 2018

Cite this article as: Gandhi, D. B. (2019). TO ASSESS THE SPECTRUM OF LESIONS IN LYMPH NODES IN HEAD AND NECK REGION. International Journal of Medical and Biomedical Studies, 3(2).

DOI: https://doi.org/10.32553/ijmbs.v3i2.638

Address for Correspondence: Dr. Bipin Gandhi, Associate Professor Dept. of Pathology, Vedanta Institute of Medical Sciences Dahanu, Palghar, Maharashtra.

Conflict of interest: No conflict of interest.

\section{Abstract}

INTRODUCTION: Lesions in head and neck have always been a diagnostic dilemma for a pathologist and a treating clinician. Being on the exposed part of body, they become cosmetically unacceptable. These include lesions arising from the regional group of lymph nodes. Most commonly lymphadenopathy is a common clinical presentation. The diagnostic probability ranges from infections to developmental abnormalities, from inflammatory to malignant lesions. None the less all the lesions in lymph nodes of the head and neck region cannot be limited to a particular age group and gender. Routine staining procedures like PAP, Giemsa, Field and even $\mathrm{H}$ \& $\mathrm{E}$ has been used to clinch the pathogenesis of the lesion. It can be said without any fear of contradiction that FNAC is certainly a very important tool for an early diagnosis of not only head and neck lesions but also other lesions elsewhere in the body.

MATERIAL AND METHODS: This is a comparative study which was conducted in the department of pathology. The patients were subjected to detailed history and thorough clinical examination according to the working proforma. Patients were subjected to FNAC after written informed concent. The slides were stained using PAP, Giemsa and H\&E stain and examined for underlying pathology. A detailed gross examination was done and 3-15 sections were selected from the representative areas for routine paraffin sections.

RESULTS: Amongst the total of 296 patients aspirated, 127 were from Lymph Nodes of head and neck region. Cervicallymph nodes were the most common group of lymph nodes aspirated, followed by submandibular and submental lymph nodes. Age wise tabulation shows maximum frequency of inflammatory lesions at younger age, of which reactive hyperplasia was more common in pediatric age group and tuberculous lesions were more common in 20-40years of age.

CONCLUSION: Cervical lymph nodes were the most common group of lymph nodes aspirated, followed by submandibular and submental lymph nodes. Reactive lymphadenitis is the most frequent diagnosis amongst the lymph node lesions and tuberculous lesions was the second most common diagnosis amongst all the lymph node lesions. 35 cases out of 127 , as tuberculous lymphadenitis. Histopathology correlation could be done in 36 cases, of which 32 were found be correctly diagnosed in cytology.

\section{Introduction:}

Lesions in head and neck have always been a diagnostic dilemma for a pathologist and a treating clinician. Being on the exposed part of body, they become cosmetically unacceptable. These include lesions arising from the regional 
group of lymph nodes'. Most commonly lymphadenopathy is a common clinical presentation. The diagnostic probability ranges from infections to developmental abnormalities, from inflammatory to malignant lesions. None the less all the lesions in lymph nodes of the head and neck region cannot be limited to a particular age group and gender $r^{\mathrm{ii}}$.

Lymph node itself presents with an etiology from a benign to a malignant lesion, non specific inflammatory to tuberculosis, lymph proliferative disorders to metastasis, and above all necrotizing lymphadenitis ${ }^{\text {iii }}$.Head and neck masses are quiet superficial and easily accessible to fine needle biopsy. It provides reliable accurate diagnosis in most of the cases. Fair patient acceptability, repeatability and avoidance of unnecessary surgical procedure have made FNAC a popular investigation $^{\text {iv }}$. A reliable fine needle aspiration if available is an advantage to both the patient and surgeon as the technique is rapid, safe, costeffective ${ }^{v}$.

Routine staining procedures like PAP, Giemsa, Field and even $\mathrm{H}$ \& $\mathrm{E}$ has been used to clinch the pathogenesis of the lesion. It can be said without any fear of contradiction that FNAC is certainly a very important tool for an early diagnosis of not only head and neck lesions but also other lesions elsewhere in the body ${ }^{\text {vi }}$.Considering all the above aspects the study was undertaken not only to evaluate but also to statistically compare the occurrence of common lesions at common and uncommon sites.

\section{CLASSIFICATION OF LYMPH NODES OF NECK ${ }^{\text {vii }}$}

There are approximately 300 lymph nodes in the neck, and they can be classified in many different ways. The American Academy of Otolaryngology and the American Joint Committee on Cancer groups the cervical lymph nodes as follows:

- Level I: Submental and submandibular nodes

- Level la: Submental triangle

- Level Ib: Submandibular triangle

- $\quad$ Level II: Upper jugular nodes
- Level III: Middle jugular nodes

- Level IV: Lower jugular nodes

- Level V: Posterior triangle group

- Level VI: Anterior compartment group

\section{Material and Method:}

This is a comparative study which was conducted in the department of pathology in Vedanta Institute of Medical Sciences Dahanu, Palghar, Maharashtra, undertaken to compare the cytological and histopathological findings in patients with head and neck masses.

A total of 296 patients with head and neck masses of either sex, who came to OPD or IPD of Vedanta Institute of Medical Sciences Dahanu, Palghar, Maharashtra.

Study Sample: Patients with head and neck masses.

\section{Method:}

1) The patients were subjected to detailed history and thorough clinical examination according to the working proforma.

2) Patients were subjected to FNAC after written informed consent.

3) The slides were stained using PAP, Giemsa and H\&E stain and examined for underlying pathology.

4) Histopathological specimen was requested and obtained from the concerned clinical department if possible.

5) The FNAC and Histopathological diagnosis were compared wherever possible.

\section{Histopathology}

1) The labeled specimen was received in histopathology department in $10 \%$ formalin.

2) A detailed gross examination was done and 3-15 sections were selected from the representative areas for routine paraffin sections.

3) Slides were stained by H\&E stain.। 
OBSERVATIONS AND RESULTS:

Table 1: Lymph Node Lesions

\begin{tabular}{|l|l|}
\hline Lmyph node lesions & No of Cases \\
\hline Reactive lymphadenitis & 54 \\
\hline Tuberculous lymphadenitis & 35 \\
\hline Abscess & 08 \\
\hline Calcified lesion & 01 \\
\hline Hodgkin's lymphoma & 04 \\
\hline Lymphoproliferative disorder & 04 \\
\hline Met. Squamous. Cell Carcinoma & 14 \\
\hline Met. Adenocarcinoma & 06 \\
\hline Malignant Melanoma & 01 \\
\hline Total & 127 \\
\hline
\end{tabular}

Table showing various types of lymph node lesions of head and neck region

Amongst the total of 296 patients aspirated, 127 were from Lymph Nodes of head and neck region. Cervicallymph nodes were the most common group of lymph nodes aspirated, followed by submandibular and submental lymph nodes. Reactive lymphadenitis is the most frequent diagnosis amongst the lymph node lesions and tuberculous lesions was the second most common diagnosis amongst all the lymph node lesions.

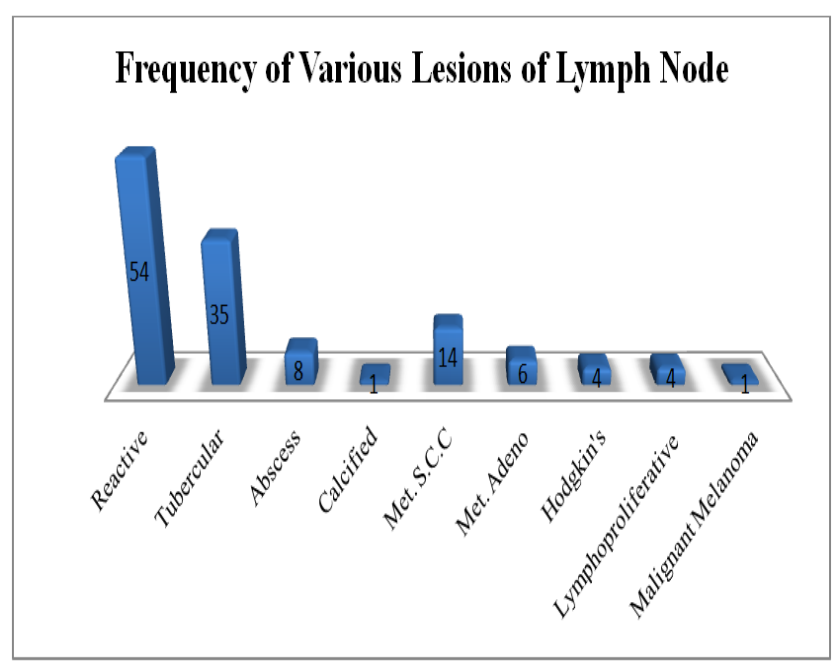

Figure 1: Bar diagram showing distribution of various types of lymph node lesions of head and neck
Table 2: Age wise distribution of the lesions arising from lymph nodes

\begin{tabular}{|l|l|l|}
\hline Age in years & Inflammatory & Malignant \\
\hline $01-10$ & 27 & 00 \\
\hline $11-20$ & 21 & 01 \\
\hline $21-30$ & 22 & 02 \\
\hline $31-40$ & 10 & 04 \\
\hline $41-50$ & 08 & 07 \\
\hline $51-60$ & 05 & 03 \\
\hline $61-70$ & 05 & 10 \\
\hline $71-80$ & 00 & 02 \\
\hline Total & 98 & 29 \\
\hline
\end{tabular}

Table no2 - showing age wise distribution of inflammatory and malignant lesions of lymph nodes of head and neck region

Age wise tabulation shows maximum frequency of inflammatory lesions at younger age, of which reactive hyperplasia was more common in pediatric age group and tuberculous lesions were more common in 20-40years of age. The incidence of malignancy keeps on increasing with the age and peak incidence was seen in 6170 years.

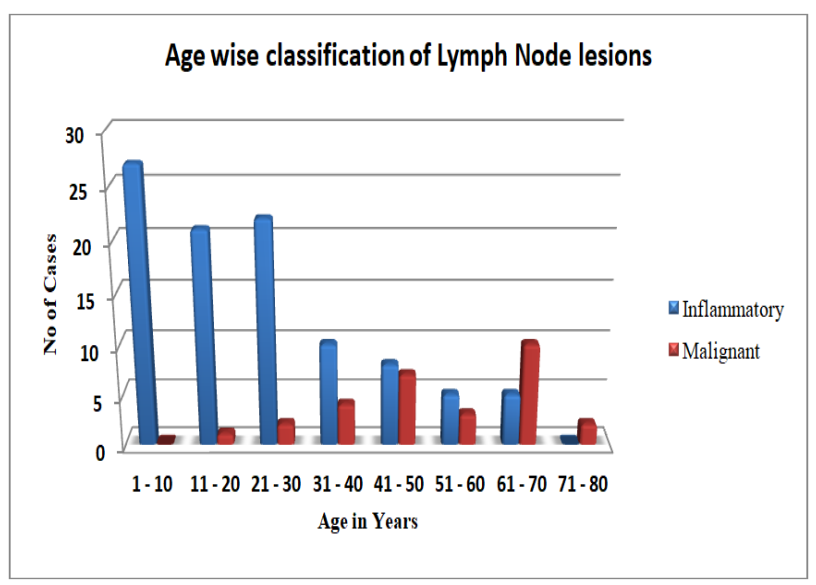

Figure 2: Bar diagram showing distribution of inflammatory and malignant lesions of lymph nodes of head and neck region

\section{Correlation of lesions of Lymph Nodes}

Amongst the 127 lymph node lesions, we could get histopathology correlation in 36 cases. The cases were tabulated in a table according to diagnosis and data was obtained 
Table 3: Showing diagnostic accuracy of cytology for tuberculous lymphadenitis

\begin{tabular}{|l|l|l|l|l|l|l|l|}
\hline \multicolumn{2}{|l|}{ Lymph Node Lesions } \\
\hline \multicolumn{2}{|l|}{ Histopathological diagnosis } & Reactive & Tuberculous & Hodgkins & $\begin{array}{l}\text { Lympho } \\
\text { proliferative }\end{array}$ & Meta. S.C.C. & $\begin{array}{l}\text { Meta. } \\
\text { Adenocarcinoma }\end{array}$ \\
\hline Reactive & 13 & 4 & 0 & 0 & 0 & 0 & 17 \\
\hline Tuberculous & 0 & 9 & 0 & 0 & 0 & 0 & 9 \\
\hline Hodgkins & 0 & 0 & 2 & 0 & 0 & 0 & 2 \\
\hline Lymphoproliferative & 0 & 0 & 0 & 0 & 0 & 1 & 1 \\
\hline Meta. S.C.C. & 0 & 0 & 0 & 0 & 4 & 0 & 4 \\
\hline Meta.Adenocarcinoma & 0 & 0 & 0 & 0 & 0 & 3 & 3 \\
\hline Total & 13 & 12 & 2 & 0 & 4 & 4 & 36 \\
\hline
\end{tabular}

As per the data obtained, Sensitivity, Specificity and Accuracy were calculated for the diagnosis of tuberculous lesions on cytology, taking histopathology as the gold standard.

\section{DISCUSSION:}

\section{Lymph Node Lesions}

Lymphadenopathy is one of the most common clinical presentations with various etiological predispositions. Lymph nodes are one of the most commonly sampled tissue for the cytological evaluation due to the fact that samples are easy to obtain and that abnormalities in lymphoid tissue are often seen in systemic as well as primary lymphoid disease ${ }^{\text {viii }}{ }^{13}$ Enlarged lymph node is one of the most frequent organ to be aspirated in the head and neck region ${ }^{i x}$. Cervical lymphadenopathy may be due to reactive lymphadenitis, specific and non specific inflammatory pathology, primary or secondary metastatic tumour of the lymph node ${ }^{x}$.FNAB offers an immediate preliminary, although not always specific diagnosis with little cost or trauma.

Bandyopadhyay et.al ${ }^{\mathrm{xi}}$.found the overall sensitivity and specificity of FNAC for cervical lymph nodes to be $93.75 \%$ \& $100 \%$ respectively in a study comprising of 50 patients with cervical lymph node enlargement.
Malakar et.al. ${ }^{\text {xii }}$ reported an overall sensitivity and specificity of FNAC to be $86.7 \%$ and $98.1 \%$ respectively.

\section{Reactive Hyperplasia:}

In the present study, out of 127 lymph nodes aspirated, 54 cases (42.51\%) were diagnosed as reactive lymph nodes. Lymph nodes were the most common aspirated organ in our study.

Percentages of reactive lymph nodes reported by other authors are compared with present study in the table below

Table 4: Comparison of reactive lymphadenitis with other studies.

\begin{tabular}{|l|l|}
\hline Author & Percentage (\%) \\
\hline Frable and Frable $^{\text {xiii }}$ (1982) & 38.00 \\
\hline Patra et.al. $^{\text {xiv }}(1983)$ & 38.10 \\
\hline Stani J $^{\text {xv }}(1987)$ & 23.50 \\
\hline Gupta et.al. $^{\text {xvi }}$ (1975) & 30.72 \\
\hline $\begin{array}{l}\text { Muhammad Javaid et. } \\
\text { al. }^{\text {xii }(2006)}\end{array}$ & 16.66 \\
\hline Present study & 42.51 \\
\hline
\end{tabular}

In present study the youngest patient was a 1 year old child and oldest was a 80 year old male. The findings of our study correlate with the study done by Patra et.al. ${ }^{14}$

\section{Abscess}

In the present study, there were 8 cases (6.3\%) of abscess. These were the cases which did not 
show any evidence of granuloma, caseous necrosis, giant cells and were also negative for acid fast bacilli by Ziehl - Neelsen stain. Culture studies of these aspirates were not performed, so the exact etiologies of these cases were not available.
Our study correlates with that of Patra et.al. ${ }^{14}$ who have reported $5.3 \%$ cases of suppurative lymphadenitis.

\section{Tuberculous Lymphadenitis:}

In the present study we reported 35 cases out of 127 , as tuberculous lymphadenitis (27.55\%).

Table 5: Comparison of tuberculous lymphadenitis with other studies.

\begin{tabular}{|l|l|l|l|}
\hline Authors & $\begin{array}{l}\text { Total Number of lymph nodes } \\
\text { aspirated }\end{array}$ & $\begin{array}{l}\text { Number of Tuberculous lymph } \\
\text { nodes }\end{array}$ & Percentage \\
\hline Patra et.al. ${ }^{14}(1983)$ & 113 & 34 & 30.01 \\
\hline $\begin{array}{l}\text { Arora \& } \\
\text { Aroraviii }(1990)\end{array}$ & 200 & 124 & 62 \\
\hline Present study & 127 & 35 & 27.55 \\
\hline
\end{tabular}

Incidence of tuberculosis in our study was comparable to the study done by Patra et $\mathrm{al}^{14}$ (1983).

\section{Correlation with Histopathology}

In our study histopathology correlation could be done in 36 cases, of which 32 were found be correctly diagnosed in cytology. Specificity was found to be $100 \%$ for diagnosis of tuberculous lesions and the sensitivity was found to be $75 \%$.

The cases of tuberculous lymphadenitis were misdiagnosed as reactive lymphadenitis on cytology. The possible reason for false negative results can be attributed to faulty aspiration technique and lack of multiple aspirations from different sites.

\section{CONCLUSION:}

1) Cervical lymph nodes were the most common group of lymph nodes aspirated, followed by submandibular and submental lymph nodes.

2) Reactive lymphadenitis is the most frequent diagnosis amongst the lymph node lesions and tuberculous lesions was the second most common diagnosis amongst all the lymph node lesions.

3) Age wise tabulation shows maximum frequency of inflammatory lesions at younger age, of which reactive hyperplasia was more common in pediatric age group and tuberculous lesions were more common in $20-40$ years of age.

4) In the present study we reported 35 cases out of 127, as tuberculous lymphadenitis.

5) Of the 127 patients with lymphadenopathy, 20 cases showed evidence of metastasis. Out of the 20 cases, 12 were males and 8 were females. The male: female ratio was 1.5:1.

6) In our study histopathology correlation could be done in 36 cases, of which 32 were found be correctly diagnosed in cytology. Specificity was found to be $100 \%$ for diagnosis of tuberculous lesions and the sensitivity was found to be $75 \%$.

\section{REFERENCES}

1. Zhang BN, Cao XC, Chen JY, et al. Guidelines on the diagnosis and treatment of breast cancer (2011 edition). Gland Surg. 2012;1(1) :39-61.

2. lacob $A$, Zazgyva $A$, Ormenişan $A$, Mezei $T$, Sin A, Tilinca M. Effectiveness of fine-needle aspiration cytology in the diagnosis of lateral cervical nonthyroid tumors. Medicine (Baltimore). 2016;95(31)

3. Nagaraju S, Vaishnav S, Burke LH, Norman EM. Histiocyticnecrotising lymphadenitis (Kikuchi-Fujimoto disease) of axillary lymph nodes. BMJ Case Rep. 2015;2015: bcr2014 203776. Published 2015 Jan 5. 
4. Poorey VK, Tyagi A. Accuracy of fine needle aspiration cytology in head and neck masses. Indian J Otolaryngol Head Neck Surg. 2014;66(2):182-186.

5. Koo V, Lioe TF, Spence RA. Fine needle aspiration cytology (FNAC) in the diagnosis of granulomatous lymphadenitis. Ulster Med J. 2006;75(1):59-64.

6. Wilkinson AR, Mahore SD, Maimoon SA. FNAC in the diagnosis of lymph node malignancies: A simple and sensitive tool. Indian J Med PaediatrOncol. 2012;33(1):21-24.

7. https://www.entnet.org/sites/default/files/ NeckDissection_QuickRefGuide_highresFINA L.

8. Mohseni $S$, Shojaiefard A, Khorgami Z, Alinejad S, Ghorbani A, Ghafouri A. Peripheral lymphadenopathy: approach and diagnostic tools. Iran J Med Sci. 2014;39(2 Suppl):158-170.

9. Lang S, Kansy B. Cervical lymph node diseases in children.GMS Curr Top Otorhinolaryngol Head Neck Surg. 2014;13:Doc08. Published 2014 Dec 1.

10. Baba Al, Câtoi C. Comparative Oncology. Bucharest: The Publishing House of the Romanian Academy; 2007. Chapter 18, CANCER DIAGNOSIS.

11. Bandyopadhyay, S.N., Roy, K.K., Dasgupta, A. et al.Role of fine needle aspiration cytology in the diagnosis of cervical lymphadenopathy. IJO \& HNS (1996) 48: 289.

12. Malakar D, Jajoo ILN, SwarupK,Gupta OP, Jain AK, Poflee VW. A clinical evaluation of Fine needle aspiration cytology in the diagnosis of lymphadenopathy. Ind. J. Tub. 1991;38:17.
13. Frable WJ, Frable MA. Fine Needle Aspiration Biopsy revisited. Laryngoscope. 1982;92(2):1414.

14. Patra AK, Nanda BK, MohapatraBVK ,Pnada AK. Diagnosis of lymphadenopathy by fine needle aspiration cytology . Indian J. Pathol .Microbiol. 1983 Oct; 26(4):273-278.

15. Stani J, Cytologic diagnosis of reactive lymphadenopathy in fine needle aspiration biopsy specimens.ActaCytol. 1987 JanFeb;31(1):8-13.

16. Gupta SK, Dutta JK, Aikat M, Gupta BD. Evaluation of Fine needle biopsy technique in diagnosis of tumours. Ind. J. Can. $1975 ; 12: 257$.

17. Muhammad Javaid, Niamatullah, Khurshid Anwar, Muhammad Said, Diagnostic value of fine needle 'aspiration cytology (FNAC) in cervical lymphadenopathy. JPMA 2006; 20 (2), 117-120.

18. Arora B, Arora DR.Fine needle aspiration cytology in diagnosis of tuberculous lymphadenitis. Indian J Med Res. 1990 May; 91:189-92. 